\title{
Study of efficiency pedestrian bridge crossing in the road of Pangerang Antasari, Banjarmasin
}

\author{
Hari Nukta Ramadani ${ }^{1, *}$, Hudan Rahmani ${ }^{1}$, and Akhmad Gazali ${ }^{1}$ \\ ${ }^{1}$ Universitas Islam Kalimantan Muhammad Arsyad Al-Banjary, Department of Civil Engineering, \\ Faculty of Engineering, Banjarmasin, Indonesia
}

\begin{abstract}
You Pedestrians are one of the highest traffic accident objects. Several ways are used to reduce the number of accidents, among others by providing road crossing facilities, such as zebra cross and pedestrian bridge crossing. Unfortunately, the utilization of such facilities, especially pedestrian bridge crossing is still very less. This condition raises the need to identify efficiency use the pedestrian bridge crossing. The study location is a pedestrian bridge crossing in the road of Pangeran Antasari, Banjarmasin City. The studies method used are survey method and analysis method. The analysis shows that pedestrian percentage that doesn't use pedestrian bridge crossing is very big, that is $87 \%$ at busy time and $88 \%$ at not busy time. The solution to increase the use of pedestrian bridge crossing is by install a curb railing fence on both sides of the road (about $200 \mathrm{~m}$ ).
\end{abstract}

\section{Introduction}

\subsection{Background}

Pedestrians are the elements of traffic that are often forgotten as part of the movement on the highway. From the number of traffic accidents that occur, pedestrians are the highest traffic object.

Several ways are used to reduce the number of accidents, including by providing road crossings, such as pelican zebra cross and pedestrian bridge crossing. Unfortunately, the utilization of such facilities, especially pedestrian bridge crossing is still very less.

\subsection{Objectives}

The main purpose of this study is to study the extent to which the efficiency of the use of pedestrian bridge crossing in the city of Banjarmasin on the road of Pangeran Antasari, In front of Mitra Plaza and looking for reasons why pedestrians use less and provide suggestions for improvement to increase the use of the pedestrian bridge crossing.

\footnotetext{
* Corresponding author: harinukta@gmail.com
} 


\subsection{Problem Definition}

The main point of this study focused on measuring the benefits of pedestrian bridge crossing, both measuring the total flow of pedestrians in each bridge during the study, as well as the percentage of pedestrians crossing over the bridge. A field survey was conducted, aiming to obtain the above variables as well as factors affecting the ratio of total pedestrians crossing by using pedestrian bridge crossing.

Surveys were conducted: pedestrian survey that crossing over bridges and on highways, traffic flows, and geometric measurements of bridges and roads.

The most important survey was the pedestrian survey that crossed over the pedestrian bridge crossing and on the highway to get the number of pedestrians using pedestrian bridge crossing.

\subsection{Influence Factors}

The influence factors studied for planning a pedestrian bridge crossing include:

- Traffic volume

- Speed of vehicle

- Comparison of time crossing

- Comparison of travel time

- Pedestrian opinions on pedestrian bridge crossing

Expectations of this study may indicate which factors are important in increasing the use of pedestrian bridge crossing.

\section{Literature Review}

Marking an ordinary pedestrian crossing is associated with an increase in the number of accidents, both pedestrian accidents and accidents involving vehicles [1]. The reason for this is not very well known, but pedestrian feeling more safe might be one possible explanation [2].

Followed from the technical aspect, pedestrian bridge or "footbridge" as defined by the Dictionary of Scientific and Technical Term that are authored by Daniel N. Lapades refer pedestrian bridge as; Footbridge is a bridge for people on foot only. According to [3], this is the best solution fo rthe pedestrians to cross the road.

Pedestrian bridge is only one way to increase road network capacity. Pedestrians who are crossing are considered to be one source of congestion [4].

Ideally, road crossing facilities should be separated from vehicle streams bridge crossings (overpass/crossingbridge/footbridge), underground crossings (subway/underpass/tunnel), and skywalk so there is no intermediate conflict pedestrians with vehicles and no delays for vehicles [5].

Crossing bridge crossing is one of the safest crossing facilities. Indeed, the construction of pedestrian bridge crossing requires a high enough cost but this value is quite valuable considering for the interests and safety of pedestrians, but the facility is underutilized because pedestrians tend not to want to change the level of the path he passes [6].

The cause of lazy pedestrians using pedestrian bridges is due to tiring, as well as unpleasant bridge conditions such as, bridge elevation, steep stairs, dirty bridge condition, and the existence of beggars. More pedestrians choose to take the risk of getting hit by a vehicle because it feels faster and more practical. Another thing that encourages pedestrians prefer the route through the road is a median road that can be used as a refuge island when crossing [7]. 
This means that the crossing bridge will only be used if the route is shorter from the route through the road. To increase the use of bridges crossings need to be applied to the guardrail at the side of the road and / or in the middle of the road so if choosing the route through the road must take that route longer or even impossible [8].

Safety factor is a main factor for respondents who tend to utilize pedestrian bridges; while for respondents who tend not to utilize pedestrian bridges, ease factors (time and distance across) became the most influential factor. So it is necessary to reduce the time and distance across to be able increase the utilization of pedestrian bridges, one possibility is by installing a guardrail either on the sidewalk or in the median [9].

From a study of pedestrian bridge crossing conducted in the Bangladesh (Dhaka), It is found that $71 \%$ pedestrians prefer underpass rather than using foot over bridge. The reasons pedestrians are not using road crossing facilities are insufficient security, time consuming, poor entrance, hawker's problem, discomfort, takes a long walk etc [10].

\section{Survey Method}

The data were collected by limiting the survey to the number of variables considered important in determining the usefulness of a pedestrian bridge crossing.

These surveys were divided, four groups:

a. Pedestrian survey, consisting of counting the number of pedestrians, crossing time conferences, comparison of travel time and pedestrian interview.

b. The traffic survey, comprised of the calculation of a large volume of traffic and the composition and speed of the vehicle.

c. The observation and measurements of pedestrian bridge crossing, consisting of dimensions, building materials, maintenance conditions, types of pedestrian bridge crossing locations and billboards sometimes attached to the bridge.

d. Geometric road, consisting of the width of the road, the direction of the vehicle flow (one-way or two-way).

Surveys of pedestrian calculations, crossings, traffic volume, and vehicle speed are performed simultaneously at the same time.

\subsection{Field Studies}

Currently in the city of Banjarmasin there is only one pedestrian bridge crossing located on the road of Pangeran Antasari in front of Mitra Plaza, this bridge is located on a busy traffic vehicle and pedestrian.

The location of these crossing bridges can be seen on the attached city map. Photos of the crossing bridges are attached.

The field survey was conducted with the help of Civil Engineering Department students from the Faculty of Engineering, Islamic University of Borneo Muhammad Arsyad AlBanjari Banjarmasin, from 1st June 2017 until 29th June 2017 for 30 days. At the appropriate time to conduct the survey, cultivated at a representative time (representative).

\section{Method of Analysis}

\subsection{Variables}

Table 1. Shows the variation in comparison of pedestrians using pedestrian bridge crossing. This is considered the most important variable to be explained in the analysis. In this analysis it is attempted to explain the comparison of $(\mathrm{Pa} / \mathrm{Pt})$, apart from other explanatory 
variables. The objective is to determine the individual relationships or relationships between variables.

Individual factors (independent variables) are taken into account where the 5 pedestrian requirements, traffic volume, vehicle speed, time of crossing, trip time comparison, pedestrian opinions and influence of billboards are also examined.

\subsection{Statistic Analysis}

In statistical analysis, Statistical and Parametic Testing is used in the analysis of this test data, in particular measuring the correlation or pooling of factors used to explain the usefulness of the pedestrian bridge crossing.

The Spearman Rank Correlation Coefficient Test is used to explore the relationship between all variables in the analysis that are not measured on a nominal scale (category).

The Eksak Fisher's probable test is used to measure the union between the variables although it is still somewhat crude, only such a way which is the most feasible alternative to this sample size and is widely used for similar problems.

\section{Result and Discussion}

Comparison of pedestrians using pedestrian bridge crossing.

Table 1. Number and Comparison of Pedestrian bridge crossing User

\begin{tabular}{|c|c|c|c|c|c|}
\hline \multirow[b]{2}{*}{ Situation } & \multicolumn{3}{|c|}{ Average number of Pedestrians } & \multirow{2}{*}{$\begin{array}{c}\% \\
\text { Under PB } \\
(\mathbf{P b} / \mathbf{P t})\end{array}$} & \multirow{2}{*}{$\begin{array}{c}\% \\
\text { Through PB } \\
\text { (Pb/Pt) }\end{array}$} \\
\hline & $\begin{array}{c}\text { Under PB } \\
\text { (Pb.o/j) }\end{array}$ & $\begin{array}{c}\text { Through PB } \\
\text { (Pa.o/j) }\end{array}$ & $\begin{array}{l}\text { Total } \\
\text { (Pt.o/j) }\end{array}$ & & \\
\hline Busy & 142 & 22 & 164 & 87 & 13 \\
\hline Not Busy & 92 & 12 & 104 & 88 & 12 \\
\hline
\end{tabular}

Table 2. Time Crossing Comparison

\begin{tabular}{|l|c|c|c|c|c|}
\hline \multirow{3}{*}{ Situation } & \multicolumn{4}{|c|}{ Average Crossing Time In Seconds } & \multirow{2}{*}{ Through/Under } \\
\cline { 2 - 5 } & $\begin{array}{c}\text { Through } \\
\text { PB }\end{array}$ & $\begin{array}{c}\text { Number of } \\
\text { Samples }\end{array}$ & $\begin{array}{c}\text { Under } \\
\text { PB }\end{array}$ & $\begin{array}{c}\text { Number of } \\
\text { Samples }\end{array}$ & \\
\hline Busy & 57 & 29 & 07 & 48 & $2.5: 1$ \\
\hline Not Busy & 56 & 16 & 21 & 35 & $2.7: 1$ \\
\hline
\end{tabular}

Table 3. Travel Time Comparison

\begin{tabular}{|l|c|c|c|c|c|}
\hline \multirow{3}{*}{ Situation } & \multicolumn{4}{|c|}{ Average Travel Time In Seconds } & \multirow{2}{*}{ Through/Under } \\
\cline { 2 - 6 } & Through PB & $\begin{array}{c}\text { Number of } \\
\text { Samples }\end{array}$ & Under PB & $\begin{array}{c}\text { Number of } \\
\text { Samples }\end{array}$ & \\
\hline Busy & 215 & 17 & 145 & 28 & $1.5: 1$ \\
\hline Not Busy & 211 & 9 & 126 & 36 & $1.7: 1$ \\
\hline
\end{tabular}


Where,

$\mathrm{Pb} \quad=$ The number of pedestrians passing under the pedestrian bridge crossing,

$\mathrm{Pa}=$ The number of pedestrians through the pedestrian bridge crossing,

$\mathrm{o} / \mathrm{j} \quad=$ people per hour,

$\mathrm{Pt}=$ Totals $(\mathrm{Pa}+\mathrm{Pb})$.

From Table 1. it can be seen that the percentage of pedestrians who do not use pedestrian bridge crossing $(\mathrm{Pb} / \mathrm{Pt})$ is very big, $87 \%$ at busy time and $88 \%$ at not busy, while using pedestrian bridge crossing $(\mathrm{P} / \mathrm{Pt})$ only $13 \%$ at Busy time and $12 \%$ at no busy time.

Table 1. also shows that if the actual flow of pedestrians using pedestrian bridge crossing is generally low (maximum of 22 people / h at busy time and 12 persons / h in non-busy time) this amount is much lower than the capacity of the bridge plan 860 persons / hour.

The relationship between the percentage of pedestrians using pedestrian bridge crossing $(\mathrm{Pa} / \mathrm{Pt})$ during busy times and pedestrian percentages using pedestrian bridge crossing at $(\mathrm{Pa} / \mathrm{Pt})$ unoccupied time can be searched with Spearman Rank Coefficient tests.

The result shows that both variables $(\mathrm{Pa} / \mathrm{Pt})$ at busy times and $\mathrm{Pa} / \mathrm{Pt}$ at no busy time have significant correlations. In non-busy times the percentage of pedestrians using pedestrian bridge crossing tends to be smaller compared to busy times.

The relationship between Percentage of Pedestrians using pedestrian bridge crossing ( $\mathrm{Pa}$ / Pt) and Total Pedestrian Needs who crossed around the Crossing Bridge (Pt) was not related.

The relationship between Percentage $(\mathrm{Pa} / \mathrm{Pt})$ and traffic volume also turned out to be unrelated, although initially before the research was conducted it was suspected of having a strong relationship. This happens because apparently the time gap between traffic platoon caused by traffic signals around the pedestrian bridge crossing.

The relationship between Percentage $(\mathrm{Pa} / \mathrm{Pt})$ and Vehicle Speed also does not exist. Either with the speed of a motorcycle, light vehicle and heavy vehicle separately or at an average speed in two directions.

The relationship between percentage $(\mathrm{Pa} / \mathrm{Pt})$ and comparison time of crossing also apparently does not exist. As shown in Table 2., the average time for the actual crossing on the pedestrian bridge crossing is 57 seconds (at busy time), 56 seconds (at not busy) and below it ranges from 23 seconds (at busy times), and 21 (when not busy). The route under the bridge is on average faster than the route through the pedestrian bridge crossing.

The relationship between percentage $(\mathrm{Pa} / \mathrm{Pt})$ and comparison of travel time also apparently does not exist. Comparison of travel time frame shown in table 3. is from 2.5: 1 at busy time and 1.7: 1 at not busy time. The time difference on the way is not too great and may be unknown to pedestrians, so another reason must be for the low use of crossing bridges. Perhaps pedestrians think that using a pedestrian bridge crossing takes a much longer time when in fact it is not, may also be related to other influences while climbing the stairs.

Pedestrian opinions about pedestrian bridge crossing for people who do not use them ground under the bridge faster, while for people who use them because they feel safe.

Crossing bridge as a crossing beacon. It turns out from observations during the survey seen more people crossing under the bridge compared with people who crossed in further positions of the bridge. 


\subsection{Billboard}

Many pedestrian bridge crossing are built by sponsors, especially for advertisements. This may be the reason why no criteria are accepted for the dimensions of the pedestrian bridge crossing, its materials or maintenance.

The negative impact of billboards is causing security problems for pedestrians using pedestrian bridge crossing. Often the boards are so high that they cover the bridge and consequently can invite crime.

Sponsors who build the crossing bridge seem to want to get the most profit from advertising. Consequently considerations of pedestrian bridge crossing design and maintenance (except the maintenance of the billboard it self) are of secondary importance. The difference in maintenance standards between pedestrian bridge crossing and billboards mounted on pedestrian bridge crossing is often very large.

\subsection{Review of Building Structures of Pedestrian Bridge Crossing}

Based on observations made on the structures and interviews with pedestrians of 3 (three) ages, children, adults and parents, as well as guidance from books on the manufacture of stairs, there is a standardization of crossing bridge designs that can provide comfort for pedestrians who use so as to increase the use of a pedestrian bridge crossing.

From the research that has been done, got the design criteria of pedestrian bridge crossing in the form of suggestion as follows:

a. For Stairs:

- Antrede $($ width of the road $)=240-200 \mathrm{~mm}($ recommended $260 \mathrm{~mm})$ Plus a flat bulge $=25 \mathrm{~mm}$.

- Optrede (high footing $)=150-130 \mathrm{~mm}($ recommended $1800 \mathrm{~mm})$.

- The slope of the stairs $-\alpha=35^{\circ}-45^{\circ}\left(\right.$ recommended $\left.35^{\circ}-38^{\circ}\right)$.

- Wide staircase $>1100 \mathrm{~mm}$ (recommended $1.250 \mathrm{~mm})$

b. For Bridge Floor:

- Net floor's width: 1700 - $1800 \mathrm{~mm}$ (Recommended according to need or min. 1800 $\mathrm{mm})$.

- High bridge's floor: 5.5 - 6.0 , For Banjarmasin recommended $4.5 \mathrm{~m}$, because there is no plan of multilevel bus usage.

General advice : $4.5-5.0 \mathrm{~m}$ (When there is no multilevel bus)

$4.5-6.6 \mathrm{~m}$ (When there is multilevel bus)

c. The height of the banister from the staircase $=800-840 \mathrm{~mm}$ (recommended $800-840$ $\mathrm{mm})$.

d. The location of the mouth and the ladder is placed in accordance with the available land, cultivated in an easily accessible place (avoid placement in the alley) and easy to see.

e. The number of mouths of the stairs depends on the pedestrian needs area.

f. The length of the crossing bridge depends on the existing road.

Drawings and details of the pedestrian bridge crossing and stair designs are shown in the accompanying drawings.

\section{Conclusion}

In general, the use of pedestrian bridge crossing in the city of Banjarmasin is very low even though this bridge is in front of the center of shops crowded with vehicular traffic and pedestrian. 
Many variables are expected to show the relationship with the use of the bridge, was found no. One is the absence of a correlation between traffic (speed and traffic flow) with pedestrians using pedestrian bridge crossing. This is because the traffic platoon and time gap are large enough to allow people to cross the road.

In terms of time comparison, crossing time using a bridge is always much larger than crossing under a bridge. It seems that saving a little time is more important for pedestrians in the city of Banjarmasin than on his personal safety.

Another reluctance factor of the user is that pedestrian bridge crossing are less maintenance (dirty), often used beggars, less secure due to shielding by sponsoring boards so pickpockets and such are easy to operate.

\section{Suggestion}

1. One way that can be used to increase the use of pedestrian bridge crossing is by set a fence on the median, under a bridge or by set a curb side fence on both sides of the road long enough (approximately $200 \mathrm{~m}$ ). This can prevent pedestrians from crossing the highway at any place and also to extend the pedestrian route to use the crossings.

2. Maintenance of crossing bridge condition is very important in its use. It is therefore recommended to maintain routine security and maintenance as well as cleaning. To build crossing bridges, design issues should be given greater priority.

3. Road safety education programs are required in schools (especially primary schools) with a fixed studies standard.

4. For the next pedestrian bridge crossing's work construction then there needs to be a comparative study of pedestrian bridge crossing and other crossing facilities (zebra cross, pelican), in the pedestrian efficient problem, cost, influence on traffic and so forth. There is also need for further study on the efficiency of the crossing bridge after the enactment of UULLAJR (Traffic Rules on The Highway) Num. 14 / 1992 to find out whether there is any difference with before the entry into force of UULLAJR.

\section{References}

1. Elvik, R., Mysen, B.A. \& Vaa, T. Trafikksikkerhetshåndbok (Traffic safety handbook). Oslo, Institute of Transport Economics. Complete Norwegian version accessable at www.toi.no. (1997)

2. Elvik, R. Which are the relevant costs and benefits of road safety measures designed for pedestrians and cyclists? Accident Analysis and Prevention. 37-45. (2000)

3. Hidayah, Nurul K. A Study on Effectiveness of Pedestrian Bridge Utilization. Faculty of Civil Engineering \& Earth Resources University Malaysia Pahang. Pahang. (2012)

4. Tamim, Ofyar Z. Perencanaan dan Pemodelan Transportasi. Second Edition, Bandung Institute of Technology. Bandung. 521p. (2000)

5. Transport And Road Research Laboratory. Toward Safer Roads in Developing Countries: A Guide for Planners and Engineers. Crowthorne, Berkshire. (1991)

6. Bruce, John A. The Pedestrian. Traffic Engineering Handbook. 3rd ed. Washington D.C. : Institute of Traffic Engineers. (1965)

7. Hartanto, Budi S. True Bridge Bridges in Bandung Less Utilized. Road and Transportation Engineering Magazine, no. 035, February: 44 - 46. (1986)

8. O' Flaherty, C.A. Transportation Planning and Traffic Engineering. Edward Arnold Ltd. London. (1997) 
9. Mosabbir, MD. Pedestrian's Behavior on Road Facilities. UTM Press. Bangladesh. (2015)

10. Setiawan, Rudy. Factors Affecting the Utilization of Pedestrian Bridges. Malang. (2006) 